\title{
A Comparative Study of the Mature Students and the Regular Students' Programmes of Delta State University, Abraka, Nigeria
}

\author{
Godwin Gideon Ogbebor ${ }^{1}$ \\ ${ }^{1}$ Guidance and Counselling Department, Delta State University, Abraka, Nigeria \\ Correspondence: Godwin Gideon Ogbebor, Guidance and Counselling Department, Delta State University, \\ Abraka, Delta State, Nigeria. Tel: 234-703-831-7959. E-mail: ggogbebor@yahoo.com
}

Received: April 2, 2012 Accepted: May 3, 2012 Published: June 1, 2012

doi:10.5539/ijps.v4n2p285 URL: http://dx.doi.org/10.5539/ijps.v4n2p285

\begin{abstract}
The research investigated academic achievement in two first degree programmes. These are the mature students' programme and the regular students' programme. The two programmes run side by side. The intention was to see whether the achievement of students in the two programmes is comparable. The mature students' programme is mounted for people of mature age, 30 years and above, while the regular students' programme has students of ages 17 to 23, but with similar entry qualifications. It was an inferential study and the design was the two-group comparison design; and it was guided by seven research hypotheses. The population was about 4,000 students, male and female, and the sample was 240. Data was collected from the second semester examination scores of 300 level courses in English Language and Modern Mathematics. The data was analysed with t-test statistic. Of the seven hypotheses tested, 3 showed no significant difference in achievement. The overall achievement, however, was in favour of students in the regular programme. The recommendation was that since the programmes are comparable, the university can justifiably run them for the first degree of the university.
\end{abstract}

Keywords: mature, regular, comparable, programme, age, achievement

\section{Introduction}

\subsection{Study Background}

The research investigated the achievement of students admitted into the mature students and the regular students' programmes of Delta State University, Abraka, Nigeria. The focus was to see how much students in the mature programme perform in their academic activities in relation to the normal regular students of the university that also run the same degree programme.

The university admits students into the mature students' programme who have the basic entry qualification to study first degree courses. These students work in different sectors of the economy, so they cannot run a normal regular programme. In addition to the basic entry qualification to read first degree courses, such students are required to have attained the age of 30 years and should be recommended and sponsored where necessary, by their employers. Those students admitted into the regular first degree programme must also possess the entry qualification of the university like the mature students. The entry qualification for both programmes is the School Certificate/General Certificate of Education. The students in the regular programme would have attained 17 years of age.

These two programmes run side by side in Delta State University, Abraka. The differences between the two programmes include the age at which students enter the programmes, and while the regular programme is full-time, the mature students' programme is part time. The regular students are resident in the university environment, while the mature students are not resident in the university. Both programmes have similar coursework load, use similar syllabus and are taught by the same lecturers and instructors. They are both examined by the same examiners although at separate occasions. The regular programme runs for four (4) sessions of two semesters per session, while the mature students' programme runs for five (5) sessions, with two semesters per session also.

The researcher intended to measure the achievement of students in the mature students' programme in relation to those in the regular programme. The purpose of this was to assess the quality of the achievement of students in the two programmes and so evaluate the certificate issued to the graduates of these two programmes by Delta State University, Abraka. 


\subsection{Research Problem}

Delta State University, Abraka runs first degree programmes for mature students and for regular students. The mature programme enrols students sponsored by their employers and whose ages range from 30 years and above. This programme is run on part-time basis. The students have the required qualification to study in the university like first degree students in any other programme. Many universities in Nigeria also mount this type of programme.

The problem of this study, therefore, was: "Would the mature students' programme and the regular students' programme in Delta State University, Abraka produce students of a comparable academic achievement?"

\subsection{Research Hypotheses}

The following hypotheses were formulated to guide the study.

Hypothesis (1): There is no significant difference in academic achievement between students in the mature programme and those in the regular programme in English Language.

Hypothesis (2): There is no significant difference in academic achievement between students in the mature programme and those in the regular programme in Modern Mathematics.

Hypothesis (3): There is no significant difference in the academic achievement of female students in the regular programme and female students in the mature students' programme in English Language.

Hypothesis (4): There is no significant difference in the academic achievement of male students in the regular programme and male students in the mature students' programme in English Language.

Hypothesis (5): There is no significant difference in the academic achievement of female students in the regular programme and female students in the mature students' programme in Modern Mathematics.

Hypothesis (6): There is no significant difference in the academic achievement of male students in the regular programme and male students in the mature students' programme in Modern Mathematics.

Hypothesis (7): There is no significant difference in the academic achievement of regular students and mature students programme.

\section{Literature Review}

\subsection{Academic Achievement}

The concept of academic achievement has to do with a means to measure success in educational institutions to see how well a student meets the standards set by an educational institution. It is a way of tracking the progress of students in the school system (Bourne, 2002). Asthana (1989) defined academic achievement to mean accomplishment of set tasks in a course objective in order to meet the requirement of an examination syllabus. It is, therefore, the application of a learning product that at the end of the process provides mastery.

On the other hand, maturity has been defined by Singh and Thukral (2010) as physical, mental and emotional aspect of behaviour with passage of time. This indicates that as time passes, there is maturity in an individual person. Maturity involves physiological changes, and changes in previous experience, knowledge and skill (Biehler, 1978).

There are reasons why people measure academic achievement. It is measured to ensure good academic results and also to ensure prospect in career choices and security (Bourne, 2002). Bourne said that academic achievement is measured to protect and ensure good school reputation and attract monetary aid from government institutions. Bourne added that academic achievement is measured as a way of assessing success in school in order to create plans for improvement in schools so as to foster improvement in the learning process, maintaining standard, for ranking of students and also to account for teacher performance. Wilke (2003) stated that success in examination is a crucial indicator that a student has benefitted from a course of study. Wilke added that British studies have relied on examination achievement and that it has since formed the basis on which academic achievement is measured by Western civilization.

Bourne (2002) also stated that there are various methods of measuring academic achievement. These include teachers' observation, summation or numerical method, written and oral tests. Others include standardized tests on a set of achievements in each age group that they are expected to meet, and measurement of students that excel in reading, mathematics, kinaesthetic and visual skill.

There are certain school subjects researchers recommend to be used to measure academic achievement. They say that not all school subjects need to be used to measure academic achievement, adding that certain school subjects 
are more suitable than others in measuring academic achievement. Masri and Almed (2007) stated that these school subjects include English Language, Modern Mathematics, Additional Mathematics, Physics and Accounts. This researcher has used two of these subjects to measure academic achievement in this study. The school subjects used are English Language and Mathematics.

\subsection{Peer-group Effect on Academic Achievements}

Adolescence is the period most students are in the regular university programme: ages 17-23 years. This is the age bracket at which peer relationship has much effect (Chauhan, 1987). The situation, however, is not the same among older students in the mature programme

Certain researchers have found significant relationship between peer group relationship and academic achievement. These researchers include Kirk (2000), Haward (2004), Ryan (2000) and Landau (2002). Kirk says that most academics recognize that a child's peers can have an impact on achievement. According to this researcher, other children as well as adults can have a great impact on a broad range of issues in the child's life, including achievement in school. He also contends that peer effect is a particularly strong influence on academic achievement and that, the peer effect is independent of other factors such as race, ethnicity, gender, income and other background variables. Kirk's research result showed that the peer effect is a strong influence on academic achievement, and that peer effect is one of the strongest determinants of academic achievement. Ungar (2000) too, observed that peer pressure is a strong factor related to school environment.

Burns and Darling (2002) and Harward (2004) defined peer effect. In their opinion, the more subtle form of peer pressure is peer influence and that it involves changing one's behaviour to meet the perceived expectation of others. Ryan (2000) found that peer groups were influential regarding changes in students' intrinsic value for school (i.e., liking and enjoying), as well as achievement which has to do with report card grades. Ryan found that associating with friends who have a positive effect towards school enhances students' own satisfaction with school, whereas associating with friends who have a negative effect towards school decreases it. Similarly, Black (2002) opined that peer pressure is important in academic achievement.

Landau (2002) stated also that an adolescent's expectancy of success was the primary predictor of academic effect and grades, adding that values that are important to most adolescents include school learning and achievement.

Researchers have investigated relationship between maturity and academic achievement, including different aspects of maturity. Singh and Thukral (2010) observed that there is significant relationship between social maturity and academic achievement of students. Chand (2007) also saw a close correlation between social maturity and academic achievement. Singh and Thukral stated that students' level of social maturity is a significant determiner of their academic achievement. West (1988) and Aggarwal (2007) had earlier found a significant positive correlation between career maturity and grade point average (GPA). West (1986) had also found that career maturity is positively related to age and GPA.

From the literature review, certain concepts have been found to be germane in relation to this study. These include concept of maturation, adolescence, age and academic achievement. Maturation has physical, social and pre-requisite skills.

\subsection{Differences of the Two Programmes}

The Delta State University Brochure specified the nature of the two programmes; the regular first degree and the part-time mature students' first degree programmes. The brochure specified the entry qualifications, the selection mode, the programme duration, and conditions students must satisfy before graduation (Delta State University Brochure 1986, 1999). The entry qualifications, the course content, conditions students must satisfy before graduation are similar for the two programmes. The differences are found in the mode of entry. For the regular programme, students must take the national selection examination (The Joint Admission and Matriculation Board Examination, JAMB). Those that enter for the mature programme do not take this entry examination. The brochure also specified the durations of the two. While the regular programme last for 4 academic calendar years; the mature students programme runs for 5 calendar years. The regular programme is full time while the mature students programme is part-time. For the mature programme, students admitted would have attained the age of 30 years.

\section{Method}

The method used to investigate the academic achievement of the regular and the mature students' programmes includes: 


\subsection{Participants}

The research used the examination scores of 300 level students in English Language and Modern Mathematics. The participants were selected using random sampling through the balloting system device. A total of 240 students' scores were used for the study out of a population of 4,000 in both the regular students and mature students' programmes, male and female. The age of the regular students whose scores were used ranged from between 17 to 23 years and that of the mature students ranged from 32 to 34 years. The study was carried out in Delta State University, Abraka, in the 2010/2011 Session.

\subsection{Research Instrument}

Scores of students in Modern Mathematics and English Language 300 level in the second semester examination were gathered for each programme and the mean computed. It was the means of both programmes that were used for the t-test analysis.

\subsection{Procedure}

The research was an inferential study that used the two group comparison design. The research collected the second semester scores in Modern Mathematics of 30 male regular students and 30 female regular students. This was also done in English Language for 30 male regular students and 30 female regular students. This gave a total of 120 regular students male and 120 female rated for English Language and Modern Mathematics.

For the mature students programme, scores for 30 male students in English Language and 30 female students' scores also in English Language were collected. It was also done for 30 male and 30 female scores in Mathematics. This gave a grand total of 240 students scores used for the study. The statistic that was used to analyse the data was the t-test. The t-test analysis was considered appropriate for the analysis because the study was concerned with determining if the two first degree programmes were comparable from evidence provided by the examination score of the two groups; and whether there was any significant difference in the achievement of students in the two programmes.

\subsection{Results}

$\mathrm{Ho}_{1}$ : There is no significant difference in academic achievement between students in the mature programme and those in the regular programme in English Language.

Table 1. T-test analysis of academic achievement between mature students programme and the regular students programme in English language

\begin{tabular}{ccccccccc}
\hline Programmes & $\mathrm{N}$ & $\overline{\mathrm{x}}$ & $\mathrm{DF}$ & $\mathrm{SD}$ & $\mathrm{t}$-calculated & t-critical & Alpha & Decision \\
\hline Regular & 60 & 57.82 & 59 & 6.698 & 4.971 & 2.001 & 0.05 & $\begin{array}{c}\text { Significant } \\
\text { Rejected }\end{array}$ \\
\hline
\end{tabular}

Table 1 reveals that the calculated $t$ - of 4.991 is greater than the critical value of $t$ which was 2.001 . Thus, there is a significant difference between the academic achievement in English Language of students in the regular programme and those in the mature students' programme. The difference is in favour of the students in the regular programme who had a mean score of 57.82 as against the mean score of 51.33 obtained by students in the mature students' programme.

$\mathrm{Ho}_{2}$ : There is no significant difference in academic achievement between students in the mature programme and those in the regular programme in Modern Mathematics.

Table 2. T-test analysis of academic achievement between mature students programme and the regular students programme in modern Mathematics

\begin{tabular}{lrrrrllll}
\hline Programmes & $\mathrm{N}$ & $\overline{\mathrm{x}}$ & $\mathrm{DF}$ & $\mathrm{SD}$ & t-calculated & t-critical & Alpha & \multicolumn{2}{c}{ Decision } \\
\hline Mature & 60 & 55.87 & 59 & 9.484 & 1.834 & 2.001 & 0.05 & $\begin{array}{l}\text { Not Significant } \\
\text { Accepted }\end{array}$ \\
Regular & 60 & 58.70 & 59 & 5.585 & & & & \multicolumn{2}{l}{ S } \\
\hline
\end{tabular}


Table 2 indicates that the calculated $t$ of 1.834 is less than the critical value of $t$ which was 2.001 at the 0.05 level of significance. Consequently, there is no significant difference between the students in the regular programme and those in the mature students' programme in terms of academic achievement in Modern Mathematics.

$\mathrm{Ho}_{3}$ : There is no significant difference in the academic achievement of female students in the regular programme and female students in the mature students' programme in English Language.

Table 3. T-test analysis of academic achievement between female students in mature students programme and the regular students programme in English language

\begin{tabular}{lrrrrrrrl}
\hline \multicolumn{1}{c}{ Programmes } & $\mathrm{N}$ & $\overline{\mathrm{x}}$ & $\mathrm{DF}$ & $\mathrm{SD}$ & t-calculated & t-critical & Alpha & Decision \\
\hline Mature & 30 & 51.00 & 29 & 6.390 & & & & \\
Regular & 30 & 58.47 & 29 & 7.385 & & 2.045 & 0.05 & $\begin{array}{l}\text { Sot } \\
\text { ignificant }\end{array}$ \\
\hline
\end{tabular}

Table 3 indicates that the calculated $t$ of 0.794 is less than the critical value of $t$ which was 2.045 at the 0.05 level of significance. Consequently, there is no significant difference between the female students in the regular programme and those female students in the mature students' programme in terms of academic achievement in English language.

$\mathrm{Ho}_{4}$ : There is no significant difference in the academic achievement of male students in the regular programme and male students in the mature students' programme in English Language.

Table 4. T-test analysis of academic achievement between male students in mature students programme and the regular students programme in English language

\begin{tabular}{lcccccccc}
\hline \multicolumn{1}{c}{ Programmes } & $\mathrm{N}$ & $\overline{\mathrm{x}}$ & $\mathrm{DF}$ & $\mathrm{SD}$ & $\mathrm{t}$-calculated & t-critical & Alpha & Decision \\
\hline Mature & 30 & 51.667 & 29 & 8.515 & 2.801 & 2.045 & 0.05 & \multicolumn{1}{c}{ Significant } \\
Regular & 30 & 57.167 & 29 & 5.989 & & & & Rejected \\
\hline
\end{tabular}

Table 4 reveals that the calculated $t$ of 2.801 is greater than the critical value of $t$ which was 2.045 . Thus, there is a significant difference between the academic achievement in English Language of male students in the regular programme and those male students in the mature students' programme. The difference is in favour of the male students in the regular programme who had a mean score of 57.167 as against the mean score of 51.667 obtained by male students in the mature students' programme.

$\mathrm{Ho}_{5}$ : There is no significant difference in the academic achievement of female students in the regular programme and female students in the mature students' programme in Modern Mathematics.

Table 5. T-test analysis of academic achievement between female students in mature students programme and the regular students programme in modern Mathematics

\begin{tabular}{lcccccccc}
\hline \multicolumn{1}{c}{ Programmes } & $\mathrm{N}$ & $\overline{\mathrm{x}}$ & $\mathrm{DF}$ & $\mathrm{SD}$ & $\mathrm{t}$-calculated & t-critical & Alpha & Decision \\
\hline Mature & 30 & 55.233 & 29 & 10.418 & & & & \\
Regular & 30 & 58.567 & 29 & 6.575 & & 2.045 & 0.05 & $\begin{array}{l}\text { Not } \\
\text { Significant } \\
\text { Accepted }\end{array}$ \\
\hline
\end{tabular}

Table 5 indicates that the calculated $t$ of 1.290 is less than the critical value of $t$ which was 2.045 at the 0.05 level of significance. Consequently, there is no significant difference between the female students in the regular programme and those female students in the mature students' programme in terms of academic achievement in Modern Mathematics. 
$\mathrm{Ho}_{6}$ : There is no significant difference in the academic achievement of male students in the regular programme and male students in the mature students' programme in Modern Mathematics.

Table 6. T-test analysis of academic achievement between male students in mature students programme and the regular Students programme in modern Mathematics

\begin{tabular}{|c|c|c|c|c|c|c|c|c|}
\hline Programmes & $\mathrm{N}$ & $\bar{x}$ & DF & SD & t-calculated & t-critical & Alpha & Decision \\
\hline Mature & 30 & 56.500 & 29 & 8.581 & 1.344 & 2.045 & 0.05 & $\begin{array}{l}\text { Not } \\
\text { Significant }\end{array}$ \\
\hline Regular & 30 & 58.833 & 29 & 4.488 & & & & Accepted \\
\hline
\end{tabular}

Table 6 indicates that the calculated t of 1.344 is less than the critical value of $t$ which was 2.045 at the 0.05 level of significance. Consequently, there is no significant difference between the male students in the regular programme and those male students in the mature students' programme in terms of academic achievement in Modern Mathematics.

$\mathrm{Ho}_{7}$ : There is no significant difference in the academic achievement of regular students and mature students programme.

Table 7. T-test analysis of academic achievement between students in the regular students programme and in the mature students programme

\begin{tabular}{|c|c|c|c|c|c|c|c|c|}
\hline Programmes & $\mathrm{N}$ & $\bar{x}$ & DF & SD & t-calculated & t-critical & Alpha & Decision \\
\hline Mature & 60 & $1.0720 \mathrm{E} 2$ & 59 & 11.978 & \multirow{2}{*}{4.791} & \multirow{2}{*}{2.001} & \multirow{2}{*}{0.05} & Significant \\
\hline Regular & 60 & $1.1652 \mathrm{E} 2$ & 59 & 8.719 & & & & Rejected \\
\hline
\end{tabular}

Table 7 reveals that the calculated $t$ of 4.791 is greater than the critical value of $t$ which was 2.001 . Thus, there is a significant difference between the academic achievement of students in the regular programme and those in the mature students programme. The difference is in favour of the students in the regular programme who had a mean score of 1.1652E2 as against the mean score of 1.0720E2 obtained by students in the mature students' programme.

\section{Discussion, Implications and Recommendation}

\subsection{Discussion}

The focus of this research was to compare the academic achievement of students admitted to read first degree through two different programmes of Delta State University, Abraka. These are the regular students programme and the mature students programme. The research wanted to see if the academic achievement of the students in the two programmes was of comparable standard.

The research found significant higher academic achievement among students in the regular programme overall, though there were some areas in which the academic achievement was comparable.

This result may be related to certain advantages regular students have. They are exposed to peer-group influence on campus which the mature students who run the programme on part-time basis do not have. Kirk (2000), Haward (2004), Ryan (2000) and Landau (2002) found positive relationship between peer-group influence and academic achievement. The relatively lower academic achievement among the mature students may also be related to the fact that these students are employed in different sectors of the economy. Many of them may have been married. This situation can also affect academic achievement because of divided attention.

Peer group influence helps to change one's behaviour to meet perceived standards of others. Harward (2004) and Ryan (2000) found that peer relation is influential in changing one's intrinsic values for school, while Landau says that an adolescent's expectancy of success is a strong predictor of academic achievement. These factors are at the advantage of students in the regular programme and they may be responsible for the group's relatively better achievement compared to the students in the mature students' programme. 
The research, however, found comparable academic achievement among the students in Mathematics in the two programmes. The researcher can confidently say that the achievement of the students in the mature programme was acceptably impressive even though it was relatively lower than that of the regular students. Singh and Thukral (2010) and West (1988) had found social maturity and career maturity to be positively related to academic achievement.

\subsection{Implications}

The results of this research showed that of the 7 hypotheses tested, 3 were rejected. This means that out of 7 aspects where the two programmes were compared, only 3 areas showed significant difference. This is an indication that, the two programmes are comparable overall. In the face of this situation, the following implications have arisen from the study.

i) The Delta State University admission of first degree students through these two programmes is justifiable.

ii) The two programmes are comparable in view of the academic achievement of the students.

iii) A cursory look at the mean academic achievement of students in the 7 hypotheses tested, showed that the relative achievement was close enough for the two programmes to run side by side.

iv) The mature students' programme gives opportunity to the working population to acquire first degree. This shows that the university is contributing reasonably to the education of the working population.

\subsection{Recommendations}

Informed by the results obtained from this research, it is recommended that Delta State University, Abraka may continue to admit students into the two programmes: the regular programme and the mature students' programme for first degree courses. In addition, other universities running the regular programme and the mature students programme may be encouraged. Finally, universities that have not started a mature students' programme should be encouraged to do so.

\section{References}

Aggarwal, V. L. (2007). Social maturity of adolescents in relation to cognitive and non-cognitive variables. Unpublished Ph.D thesis, Punjab University, Chanigarh.

Biehler, R. F. (1978). Psychology applied to Teaching. Boston, Houghton: Mifflin Company.

Black, S. (2002). When students push past peer influence. The Education Digest, 68, 31-36.

Bourne, P. A. (2002). The influence of Social factors on academic performance. Unpublished M.Sc. Thesis, University of West Indies, Kingston, Jamaica. Retrieved from http://www.ehow.com/about 4740750 definehtml\#ixzz

Burns, A., \& Darling, N. (2002). Peer pressure is not peer influence. The Education Digest, 68, 4-6.

Chand, R. (2007). Social maturity among student teachers, Education. New horizons, Quarterly Journal of Education.

Chauhan, S. S. (1981). Advanced Educational Psychology. New Delhi: Yikasd Publishing House, PVT Ltd.

Delta State University Brochure (1986). Regulation for first degree programme. DELSU - Abraka. University Printing Press.

Delta State University Brochure (1999). Regulation for first degree mature students programme. DELSU Abraka. University Printing Press.

Haward, N. M. (2004). Peer influence in relation to academic performance and socialization among adolescents: Literature Review. M.Sc. Paper presented at University of Wisconsin-Stout.

Kirk, A. J. (2000). The peer effect on academic achievement among public elementary school students. A Report of the Heritage Centre for Data Analysis. Retrieved from http:// www.heritage.org

Landau, A. (2002). Peer groups and educational outcomes. Retrieved from http://www.ehow

Nasri, K., \& Ahmed, R. (2007). Factors affecting business students' performance: The case of students in United Arab Emirate. Journal of Education for Business. Retrieved from http://www.cscanada.org

Ryan, A. M. (2000). Peer groups as a context for the socialization of adolescents' motivation engagement, and achievement in school. Educational Psychologist, 35, 101-112. http://dx.doi.org/10.1207/S15326985EP3502_4 
Singh, S., \& Thukral, P. (2010). Social maturity and academic achievement of high school students. Canadian Journal on Scientific and Industrial Research, 1(1).

Ungar, M. T. (2000). The Myth of Peer Pressure. Adolescence, 35,165-180.

West, D. K. (1988). Comparisons of career maturity and its relationship with academic performance. Journal of American Indian Education.

Wilke, R. R. (2003). The effect of active learning on students' characteristics in a Human Psychology course for non-majors. Advances in Physiology Education, 27(4). http://dx.doi.org/10.1152/advan.00003.2002 